\title{
Proteolytic Characterization and Lysosomal Localization of Echinoderm Cathepsin D
}

\author{
Ajith kumar and Siva Kumar $\mathbf{N}^{*}$ \\ Protein Biochemistry and Glycobiology Laboratory, Department of Biochemistry, University of \\ Hyderabad, Hyderabad, 500046, India
}

Received: January 06, 2018; Accepted: January 29, 2018; Published: January 31, 2018

*Corresponding author: Siva Kumar N, Protein Biochemistry and Glycobiology Laboratory, Department of Biochemistry, University of Hyderabad, Hyderabad, 500046, India, Tel: +91-40-23134569; Fax:+91-40-23010120; E-mail: nsksl@uohyd.ernet.in, knadimpalli23@gmail.com

\begin{abstract}
Cathepsin D is an important lysosomal aspartic protease and is transported to the lysosomes in both mannose 6-phosphate dependent and independent manner. The present study reports lysosomal transport and proteolytic characterization of cathepsin D purified from gonads of starfish Asterias Rubens. Activity of the purified enzyme was confirmed by a zymogram assay on hemoglobin Characterization of proteolytic activity on bovine serum albumin and ovalbumin showed that the enzyme cleaves these proteins with high specificity when compared to human enzymes. Lysosomal localization of the purified enzyme in human embryonic kidney cells was studied using Fluorescein isothiocyanate conjugated enzyme and anti-goat cation independent mannose 6-phosphate receptor antibody. Primary sequence based studies and phylogenetic analysis showed that the echinoderm cathepsin D is more related to plant aspartic protease phytepsin and may have three intra molecular disulfide linkages. The results show that the lysosomal transport of the enzyme in marine invertebrates is facilitated through the mannose 6-phosphate (m6-p) receptor mediated pathway even though m6-p independent pathways for homologues of the enzyme are also prevalent in higher organisms.
\end{abstract}

Key words: Cathepsin D; Mannose 6-phosphate receptor; Aspartic protease; Lysosomal transport;

\section{Introduction}

Cathepsin D is an aspartic endoproteinase present both in lysosomes and cytosol of mammalian cells. Lysosomal cathepsin $\mathrm{D}$ is an important lysosomal protease and is responsible for the majority of lysosomal proteolysis accounting for $10 \%$ of all lysosomal proteins $[3,20]$. Cathepsin D is synthesized in the rough endoplasmic reticulum as pre-procathepsin $\mathrm{D}$ and the pre-pro form of the enzyme is converted to procathepsin $\mathrm{D}$ by the removal of signal peptides. The procathepsin D then undergoes posttranslational modifications required for lysosomal transport and active forms of the enzymes are formed by proteolytic cleavage of the proenzyme by autocatalysis and by other proteases through a pseudocathepsin D intermediate [13]. The substrate specificity of the mature enzyme varies depending on the cell type and function.
Mammalian cathepsin D possesses a high variability in substrate specificity and proteolitic cleavages are believed to occur when hydrophobic amino acids are present at both the $\mathrm{N}$ and $\mathrm{C}$ termini of the cleavage site. In addition to this, the hydrophobic scores formed by neighboring amino acids of the cleavage site also add to the efficiency of the cleavage [17]. The active site of the cathepsin D is formed by two aspartic acid residues located at 33 and 231 positions in the order Asp-Thr-Gly [11].

Mammalian cathepsin $\mathrm{D}$ is a $44 \mathrm{kDa}$ glycoprotein in its functional form and is transported to lysosomes in both the mannose 6-phosphate and sortilin dependent manner. Mannose 6-phosphate receptors CIMPR and CDMPR(Cation Independent Mannose 6-phosphate receptors and Cation dependent mannose 6-phosphate receptors) bind and transport the mature enzyme to the lysosomes using the former pathway. Another lysosomal enzyme sorting protein sortilin assists the transport of cathepsin D to lysosomes in the later $[4,5]$. Both pathways act in synergy and one often complements in the absence of the other for the efficient lysosomal transport of cathepsin D. Both the receptors have been identified in mammals and putative homologs of the receptors responsible for the transport of lysosomal enzymes have been identified in echinoderms and mollusks [12]. Recent studies have reported the properties of lysosomal enzymes and their possible receptor-mediated lysosomal transport in invertebrates [7]. As the starfish cathepsin D has been affinity purified and preliminarily characterized [10], the present study was undertaken to gain new insights into two important properties of the enzyme (i) comparing its proteolytic activity against mammalian proteins and (ii) to study the MPR mediated lysosomal localization of the purified enzyme in mammalian cells.

\section{Materials and Methods}

\section{Zymogram assay}

Starfish Asterias Rubens, collected from the off Kiel coast, North Sea, Germany was provided by Sorge Kelm, University of Bremen. Total proteins were separated using $80 \%$ ammonium sulfate precipitation and cathepsin D was purified according 
to [10]. A zymogram assay was conducted to qualitatively determine the activity of the enzyme in gel using hemoglobin $(\mathrm{Hb})$ as substrate [19]. A native PAGE was polymerized with $0.2 \% \mathrm{Hb}$ and purified cathepsin D was loaded onto the gel. After the electrophoretic run, the gel was washed three times for 10 minutes with $100 \mathrm{mM}$ Tris-HCl buffer $\mathrm{pH} 7.4$ and incubated in activity buffer $0.1 \mathrm{M}$ sodium acetate pH 6 with 1mM EDTA and $2 \mathrm{mM}$ DTT for 30 minutes at room temperature and then overnight at $37^{\circ} \mathrm{C}$. Later the gel was stained with Coomassie brilliant blue G250 for 2-3 hours and a clear zone of activity was observed after destaining the gel. Destaining was achieved by incubating the gel in a rocker with destaining solution (50\% Methanol, 10\% acetic acid solution in water) until zone of activity was observed.

\section{Proteolytic characterization}

Purified cathepsin D was dialyzed against $50 \mathrm{mM}$ sodium acetate buffer $\mathrm{pH} 3.5$ and used for further studies. Protein substrates for determining the proteolysis of cathepsin D were prepared by dissolving $150 \mathrm{nM}$ proteins (BSA, ovalbumin) in $100 \mathrm{mM}$ sodium citrate buffer, $\mathrm{pH} 3.5$ and 4.5 and incubated with $20 \mu \mathrm{L}$ of purified enzyme for 15 minutes to 3 hours at $37^{\circ} \mathrm{C}$. The reaction was stopped by incubating in cold after each time interval. $40 \mu \mathrm{L}$ of each mixture was added with SDS sample buffer and loaded to a $10 \%$ SDS PAGE. The cleaved products were visualized using silver nitrate staining [17].

\section{Lysosomal localization of starfish cathepsin D}

The endocytosis of the enzyme was studied by incubating cathepsin D and an anti cathepsin D polyclonal antibody developed previously with Human Embryonic Kidney (HEK) cells grown to $80 \%$ confluency on sterile glass cover slips in complete DMEM medium at $37^{\circ} \mathrm{C}$. Following incubation, cells were washed with PBS three times and fixed in 14\% paraformaldehyde for 20 minutes at room temperature. Fluorescein Isothiocyanate (FITC) conjugated secondary antibody was used to determine the presence of cathepsin D in the cells. About 1mg of purified cathepsin D was incubated with $550 \mu$ of borate buffer $(50 \mathrm{mM}$, $\mathrm{pH} \mathrm{9.0)} \mathrm{and} 100 \mathrm{ml}$ of flurochrome solution of fluoresceinisothiocyanate (5 mg FITC dissolved in $1 \mathrm{~mL}$ of DMSO) was added to the enzyme sample, mixed well and the sample stored overnight at $4^{\circ} \mathrm{C}$ in the dark. Free FITC was removed by desalting using a Sephadex G-25 gel. For the co-localization study, cells were also treated with rabbit anti-goat CIMPR antibody developed in an earlier study having 1:200 dilutions in PBS containing 1\% BSA [18]. The cells were washed and incubated with fluorescently tagged anti-rabbit IgG-Alexa flour 594 for 1 hour at room temperature. Finally the cells were stained with DAPI and observed under a confocal microscope (Leica TCS SP5 Confocal Microscope).

\section{Results}

\section{Zymogram assay}

Cathepsin D activity was observed as a clear zone of activity in the Hb co-polymarized native gel (Figure 1)

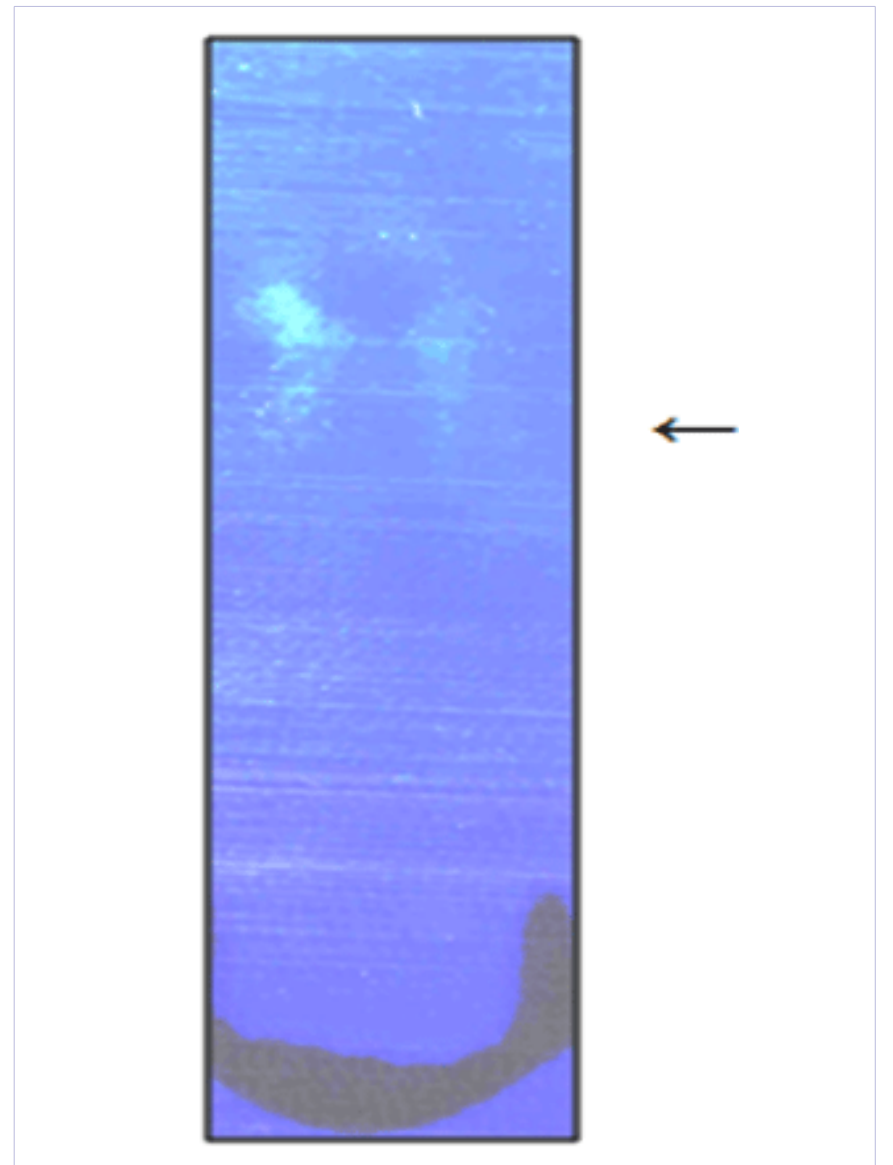

Figure 1: Zymogram assay of starfish cathepsin D: Proteolytic activity of the purified cathepsin D was observed in a PAGE co-polymerized with $0.2 \%$ hemoglobin. Cathepsin D activity was observed as a clear zone of activity on Coomassie staining of the gel $(\leftarrow)$.

\section{Proteolytic characterization}

Time dependent proteolytic assays using BSA and ovalbumin showed that enzyme cleaved both proteins under test conditions. At $\mathrm{pH}$ 3.5, BSA was cleaved into a number of smaller peptides (Figure 2A) while at $\mathrm{pH} 4.5$, two cleaved products appeared of 44 and $21 \mathrm{kDa}$ molecular weight (Figure 2B). On ovalbumin, the enzyme showed limited cleavage at lower $\mathrm{pH} 3.5$, where no cleavage was shown at $\mathrm{pH} 4.5$. Ovalbumin was also cleaved into two peptides at pH 3.5 (Figure 2C).

\section{Lysosomal localization of starfish cathepsin D}

Lysosomal localization of purified cathepsin D was studied in HEK cells using two strategies. First the supplemented FITC conjugated cathepsin D was probed in the cell using anticathepsin D antibody developed in an earlier study [10] showed that the cathepsin D is internalized into the cells (Figure 3 panel I). No fluorescence was observed in a control experiment where only the secondary antibody was used (Figure 3 - panel II). Co localization of FITC-conjugated cathepsin with the CIMPR receptor was observed when cells were incubated with fluorescently tagged receptor antibody (Figure 3 - panel III). 
A

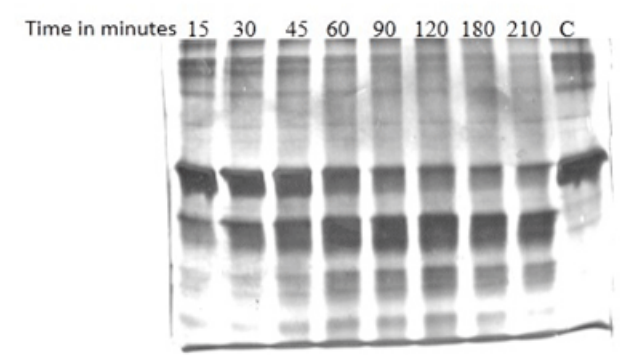

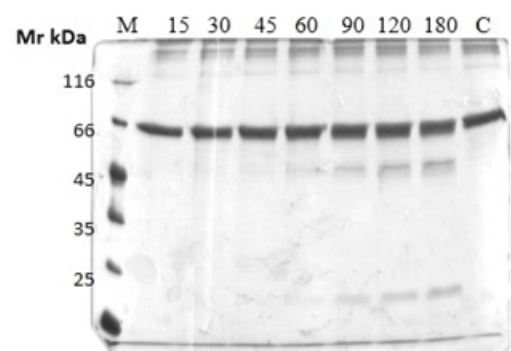

C

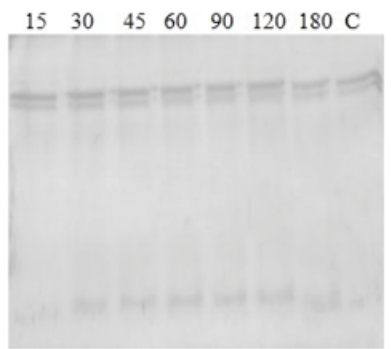

Figure 2: Proteolytic cleavage of starfish cathepsin D on BSA and ovalbumin in a time dependent assay: A. cleavage of BSA at pH 3.5, B. cleavage of BSA at pH 4.5, C. Cleavage of ovalbumin at pH 3.5 (lanes: samples from assays with duration in minutes as indicated at the top of the figures, $\mathrm{M}$ molecular weight markers, $\mathrm{C}$ control in the results section $\mathrm{C}$ is ovalbumin which was calved into two peptides)

I
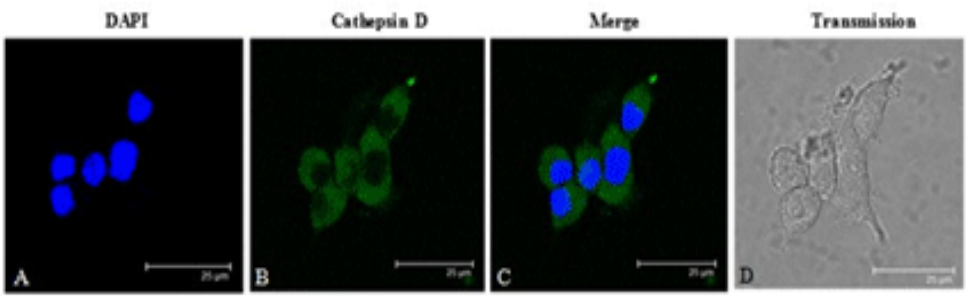

II

II

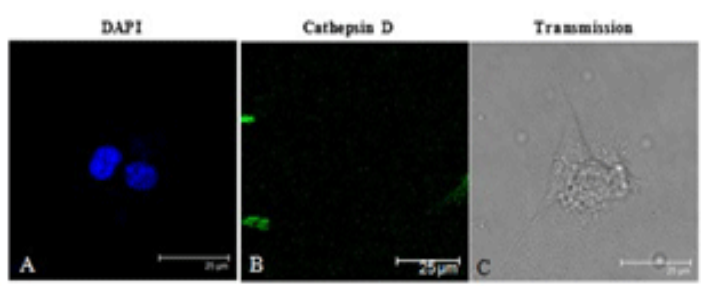

II
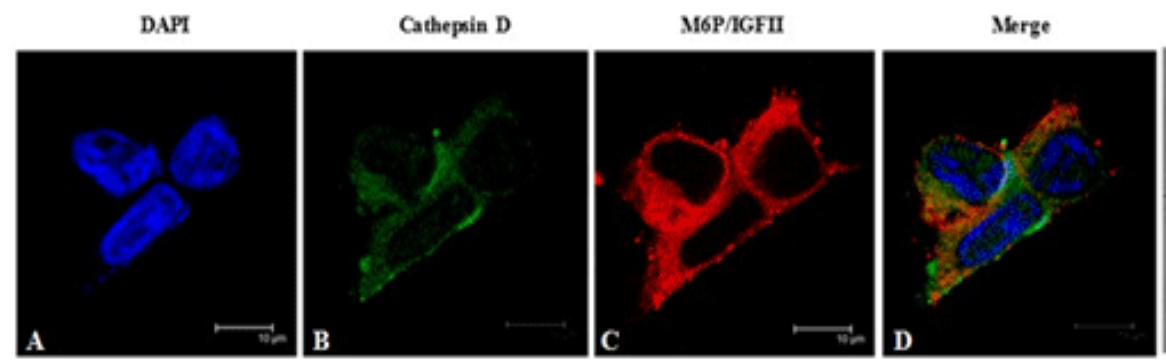

Transmission

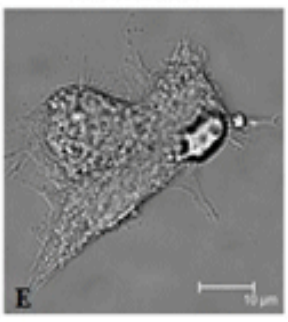

Figure 3: Immunofluorescence of cathepsin D: I (A) DAPI stain,(B) probed with cathepsin D specific IgG (1:100 dilution) followed by incubation with FITC conjugated secondary antibody (green) (1:1000 dilution) (C) merged images of A \& B, (D) image developed in transmission mode. II (A) DAPI stain, (B) incubation with only FITC conjugated secondary antibody (green) (1:1000 dilution). (C) Image developed in transmission mode. Bar in both panel I \& II is $25 \mu \mathrm{m}$. III (A) DAPI , (B) FITC conjugated cathepsin D, (C) incubation with goat MPR 300 antibody followed by fluorescently tagged anti-rabbit IgG-Alexa fluor 594 (red) secondary antibody, (D) is merged images of A,B \& C, (E) is the image developed in transmission mode. Bar in the panel is $10 \mu \mathrm{m}$. 


\section{Discussion}

The present study extends our previous report on the purification of lysosomal cathepsin D from Asterias Rubens. Cathepsin D was purified from the gonads of the organism using pepstatin affinity chromatography and tested for its proteolytic activity and lysosomal transport [10]. Zymogram assays performed on hemoglobin suggested that the purified enzyme exhibited protease activity at acidic $\mathrm{pH}$, which was confirmed by measuring the release of peptides when incubated with acidified hemoglobin (data not shown). The specificity and mechanism of proteolysis by the enzyme remained unclear until it was revealed that the hydrophobicity of neighboring amino acids are important in determining the cleavage site of mammalian cathepsin D. In time-course assays with $\mathrm{Hb}$, the cleavage products released by starfish cathepsin D was limited to a few peptides for BSA, indicating that the enzyme has more proteolytic specificity

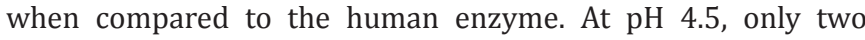
peptides were present in the solution indicating that cleavage is even more specific and $\mathrm{pH}$ dependent under cellular conditions

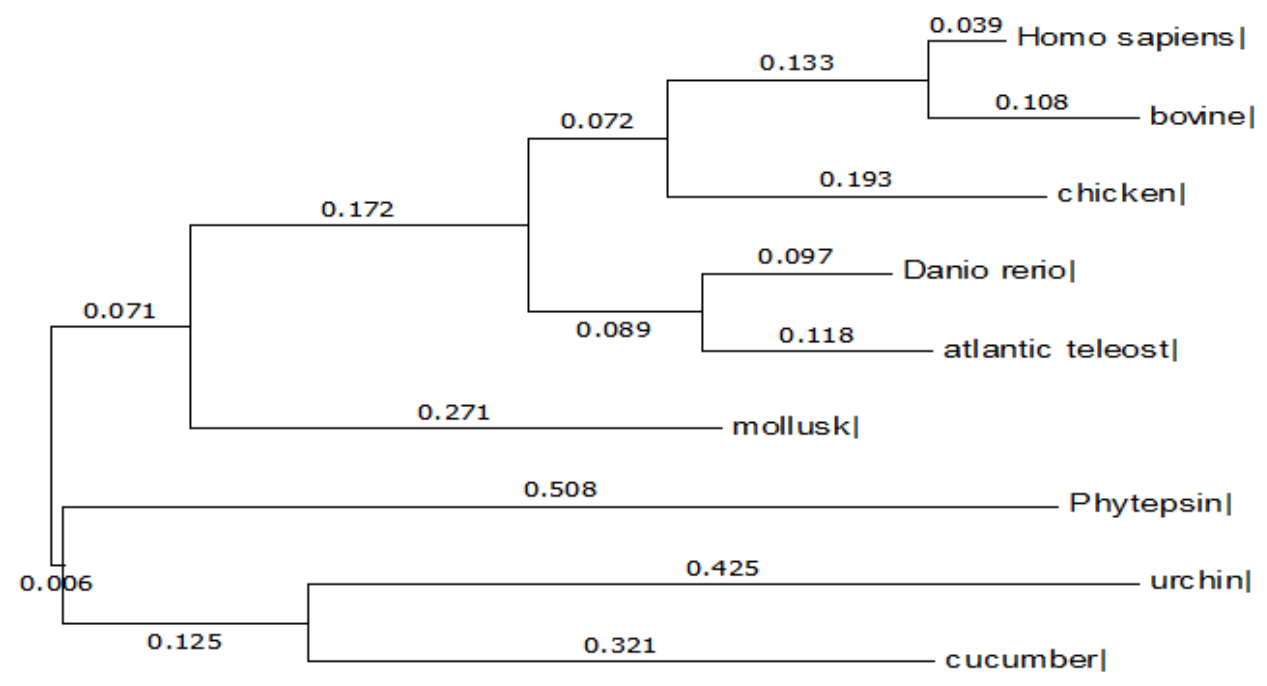

B

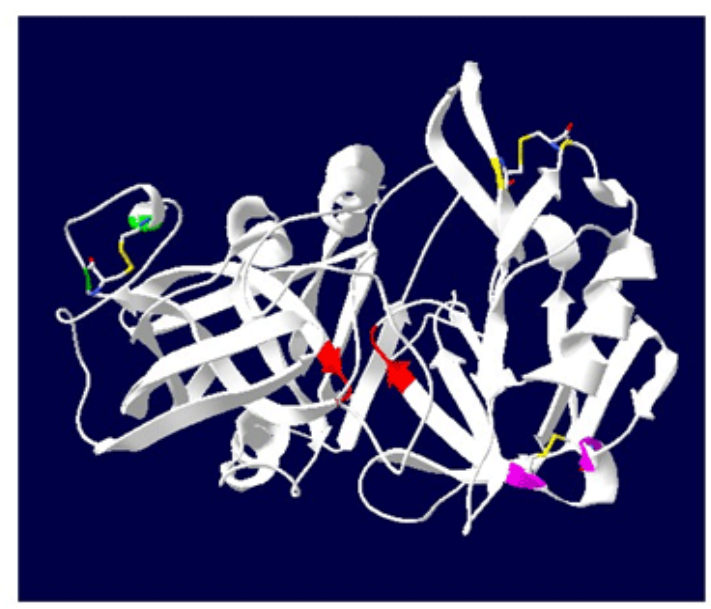

Figure 4: Phylogenetic tree and three dimensional structure of echinoderm cathepsin D: (A) A phylogenetic tree constructed according to software routine of MEGA 7.0 with cathepsin D, (B) Predicted model of echinoderm cathepsin D with active site amino acids in red and possible disulfide linkages. 
(at lysosomal pH of 4.5-5). Further, the products of 45 and 21 $\mathrm{kDa}$ molecular weight, suggest that BSA is cleaved exactly into two peptides at a Phe- 441, a previously reported cleavage site for human cathepsin D [1]. The starfish enzyme might have a preferred cleavage site on BSA at Phe- 441 as well. The cleavage of ovalbumin also yielded two peptides similar to the proteolysis on BSA, but at lower pH. These results suggest that the starfish cathepsin D has greater proteolytic specificity than the human enzyme. Reduced specificity in the mammalian enzyme might be an evolutionary advantage enabling the mammalian cathepsin D to degrade more proteins present in the lysosomes.

The lysosomal transport of cathepsins is mediated by both Mannose 6-phosphate receptors and sortilin [9]. The present study using HEK cells proved that the lysosomal cathepsin D of starfish possesses the post translational modifications required for the transport of the enzyme through mannose 6-phoshate receptors. The internalization of cathepsin D was first established using the cathepsin D antibody and FITC conjugated anti-rabbit antibody. The co-localization of both CIMPR and cathepsin D indicated that internalization and lysosomal transport was mediated by the receptor. In addition to the mannose 6-phoshate receptors, sortilin may play a role in lysosomal transport of this enzyme which needs to be validated with additional experiments $[4,7]$. However, previous reports of both the mannose 6-phosphate receptors in invertebrates such as echinoderms and mollusks indicates the lysosomal biogenesis in these organisms follows mannose 6-phosphate dependent pathways which is found to be evolutionarily conserved in higher vertebrates including mammals [21].

A multiple sequence analysis and construction of phylogenetic tree using the maximum likelihood method in Mega 7.0 software was used to compute the similarity between the invertebrate cathepsin D to the plant protease phytepsin [6,8].In addition to the amino acid sequence similarity, phytepsin was closer to echinoderms in the constructed tree indicating the evolutionary relatedness between the plant and invertebrate aspartic endoproteases (Figure 4A). Swiss PDB viewer [16] was used to predict the three dimensional structure of echinoderm cathepsin D (Strongylocentrotus purpuratus, ID:XP_011673029.1). According to the primary sequence analysis, echinoderm cathepsin D shows the possibility of three disulfide linkages instead of four present in the human enzyme [2].The predicted three-dimentional structure of sea cucumber cathepsin D using Swiss PDB viewer (Figure 4A), [16] indicates three disulfide bridges at positions cys $100-107$, cys $266-271$ and cys $310-347$. A three dimensional model of the enzyme indicating the disulphide linkages (green, violet and yellow) and active site aspartic acids (red) is portrayed in (Figure 4B). Increased number of disulfide linkages might enhance the stability of mammalian enzymes.

In summary the present study reports the functional characterization of the starfish cathepsin D. On one hand it shows specific proteolytic cleavage of proteins in acidic $\mathrm{pH}$ and this appears to be more specific when compared to the mammalian protein and exhibits a similar pattern of transport to the lysosomes as described for the mammalian enzyme (CIMPR mediated transport) as evidenced from confocal studies. Additionally, echinoderm cathepsin D is more similar to plant aspartic protease phytepsin in phylogenetic analysis. Amino acid sequence based predictions indicate that the echinoderm cathepsin D bears three cysteine disulfilde linkages instead of the four linkages found in the human enzyme.

\section{Acknowledgement}

AAK thanks CSIR for a research fellowship. Research work in the laboratory of NSK is supported by funds from IRTG-MCGS (GRK 1549: DFG, Germany and UGC, India). We thank Merino Visa for the confocal experiment. The infrastructural facilities from the DST-FIST Program and the financial support from UGC-SAPDRS-1 program provided to the Department of Biochemistry are gratefully acknowledged.

\section{References}

1. Arnold D, Keilholz W, Schild H, Dumrese T, Stevanović S, Rammensee HG. Substrate Specificity of Cathepsins D and E Determined by N-Terminal and C-terminal Sequencing of Peptide Pools. Eur J Biochem. 1997;249(1):171-179.

2. Baldwin ET, Bhat TN, Gulnik S, Hosur MV, Collins J, Silva AM, et al. Crystal structures of native and inhibited forms of human cathepsin D: implications for lysosomal targeting and drug design. Proc Natl Acad Sci. 1993;90(14):6796-6800.

3. Benes P, Vetvicka V, Fusek M. Cathepsin D-Many functions of one aspartic protease. Crit Rev Oncol Hematol. 2008;68(1):12-28. doi: 10.1016/j.critrevonc.2008.02.008

4. Canuel M, Korkidakis A, Konnyu K, Morales CR. Sortilin mediates the lysosomal targeting of cathepsins D and H. Biochem Biophys Res Commun. 2008;373(2):292-297. doi: 10.1016/j.bbrc.2008.06.021

5. Conner GE. The role of the cathepsin D propeptide in sorting to the lysosome. J Biol Chem. 1992;267(30):21738-21745.

6. Jones DT, Taylor WR, Thornton JM. The rapid generation of mutation data matrices from protein sequences. Comput Appl Biosci. 1992;8(3):275-282.

7. Kumar NS, Bhamidimarri PM. Lysosomal Enzymes and their Receptors in Invertebrates: An Evolutionary Perspective. Curr Protein Pept Sci. 2015;16(1):49-65.

8. Kumar S, Stecher G, Tamura K. MEGA7: Molecular Evolutionary Genetics Analysis Version 7.0 for Bigger Datasets. Mol Biol Evol. 2016;33(7):1870-1874. doi: 10.1093/molbev/msw054

9. Libin Y, Morales CR, Canuel M. The interactomics of sortilin: an ancient lysosomal receptor evolving new functions. Histol Histopathol. 2009;24(4):481-492. doi: 10.14670/HH-24.481

10. Merino V, Siva Kumar N. Isolation, affinity purification and biochemical characterization of a lysosomal cathepsin D from the deuterostome Asterias Rubens. Comp Biochem Physiol B Biochem Mol Biol. 2012;161(3):240-246. doi: 10.1016/j.cbpb.2011.11.013

11. Minarowska A, Gacko M, Karwowska A, Minarowski Ł. Human cathepsin D. Folia Histochem Cytobiol. 2008;46(1):23-38. doi: 10.2478/v10042-008-0003-x 
12. Nadimpalli SK, Amancha PK. Evolution of mannose 6-phosphate receptors (MPR300 and 46): lysosomal enzyme sorting proteins. Curr Protein Pept Sci. 2010;11(1):68-90.

13. Richo G, Conner GE. Proteolytic activation of human procathepsin D. Adv Exp Med Biol. 1991;306:289-296.

14. Runeberg-Roos P, Törmäkangas K, Östman A. Primary structure of a barley-grain aspartic proteinase. A plantaspartic proteinaseresembling mammalian cathepsin D. Eur J Biochem. 1991;202(3):1021-1027.

15. Sarkkinen P, Kalkkinen N, Tilgmann C, Siuro J, Kervinen J, Mikola L. Aspartic proteinase from barley grains is related to mammalian lysosomal cathepsin D. Planta. 1992;186(3):317-323. doi: 10.1007/ BF00195311

16. Schwede T, Kopp J, Guex N, Peitsch MC. SWISS-MODEL: an automated protein homology-modeling server. Nucleic Acids Res. 2003;31(13):3381-3385
17. Sun H, Lou X, Shan Q, Zhang J, Zhu X, Wang Y, et al. Proteolytic Characteristics of Cathepsin D Related to the Recognition and Cleavage of Its Target Proteins. PLoS ONE. 2013;8(6):e65733. doi: 10.1371/ journal.pone.0065733

18. Suresh K, Nadimpalli SK. An immuno-affinity method for the purification of mannose 6-phosphate receptor proteins. J Biochem Biophys Methods. 2003;57(3):237-245.

19. Wilder CL, Park KY, Keegan PM, Platt MO. Manipulating substrate and $\mathrm{pH}$ in zymography protocols selectively distinguishes cathepsins $\mathrm{K}, \mathrm{L}, \mathrm{S}$, and V activity in cells and tissues. Arch Biochem Biophys. 2011;516(1):52-57. doi: 10.1016/j.abb.2011.09.009

20. Wittlin S, Rösel J, Stover DR. One-step purification of cathepsin D by affinity chromatography using immobilized propeptide sequences. Eur J Biochem. 1998;252(3):530-536.

21. Yadavalli S, Nadimpalli SK. Mannose-6-phosphate receptors (MPR 300 and 46) from the highly evolved invertebrate Asterias Rubens (Echinodermate): biochemical and functional characterization of MPR 46 protein. Glycoconj J. 2008;25(9):889-901. doi: 10.1007/s10719008-9153-5 